\title{
Current challenges and opportunities for orthodontics: An optimist's views
}

$\mathbf{R}_{\text {ecently I was reminded by an esteemed }}$ colleague in practice that orthodontics is a mixture of art, science, and business. As he happened to be the father of one of my graduate students, I began to think about his statement, and I wondered just how well we are doing in preparing his son to follow in his footsteps.

Orthodontists are a special breed. It is doubtful if any other health professionals are more agonizingly self-critical or set themselves higher standards of clinical performance. Although we do not deal with lifeendangering conditions as a rule, there is a general quest for perfection in our treatment and a concern with long-term results in terms of stability, function, and esthetics. Few, if any, medical specialties deem it a failure if their patients are not completely and permanently cured! By contrast, if our best efforts yield a significant improvement, but not a permanently maintained and ideal form-function relationship in the craniofacial complex, we are dissatisfied.

The question is: Can we really do much better with our present knowledge and techniques? My personal view is that in the current situation we can and will, but we should not be subjected to these feelings of guilt and frustration that our perfectionist ethic produces. This statement should not be misconstrued as advocating a lowering of standards nor as justification for a deliberate disinterest in the long-term welfare of our patients. Such a disavowal of dedicated service to the public is not only alien to, but incompatible with, the survival of a health profession.

There is, however, a cure for our various predicaments, and the prospect for resolving many of our common concerns has never been brighter. My principal premise is that in orthodontics the three facets of art, science, and economics are indivisible and intimately related. It therefore follows that resolution of problems in any one of these three areas must be reconciled with the whole.

The economic problems and realities that orthodontists face today stem from a variety of factors. These include an increase in the number of providers, both within and outside the specialty, coupled with a relative decline in demand. Endeavors to increase popular awareness of the availability of services, using marketing techniques that work in business, are a natu- ral reaction by our profession. However, there is danger that such a strategy may result in promoting an image of self-interest and a decline in the public's respect and trust of orthodontists as altruistic health professionals. It may seem somewhat cynical, but nevertheless it is probably true to say that altruism is a form of enlightened self-interest. Advertising, even if it is called "public education," may be a quick fix; the long-term solution requires a very different approach. The viability of most major medical specialties resides not in self-promotion but in the demonstrable superiority of the services that they provide. Modern medicine is demanding and expensive, but its progress and prosperity are predicated on the incorporation of biomedical research into everyday practice and the replacement of art and empiricism by science. With the knowledge explosion generated by research, patterns of practice must change to incorporate new information at an ever-increasing pace. We should endeavor to narrow this gap between art and science in orthodontics. There is danger of a dichotomy between the technology necessary for treatment and the biologic foundations of our diagnosis and therapy. ${ }^{*}$ With the advent of combined orthodontic and surgical treatment and an increasing awareness of the modifiability of growth, there has been a remarkable widening of the spectrum of services that we now offer.

Today it is essential that we educate orthodontists and not simply train them. Traditional training has always included a smattering of biology but was concerned predominantly with the acquisition of technical "know-how" and the accumulation of experience prior to entering private practice. This pattern of training, unfortunately, rendered orthodontists vulnerable in terms of adaptability to some major changes in our specialty that have occurred in the recent past and that promise to become even more remarkable in the future. Many clinicians now lack the confidence to evaluate critically some of the newer treatment modalities. This is particularly true if innovations are promoted by enthusiasts in a convincing and unchallenged manner. At present, empirical pragmatism sometimes seems more convincing than scientific data. The thriving industry of

*Editorial, Am. J. Orthod. 83:353-353, April. 1983 
continuing education, outside the auspices of academic institutions, attests to the unquenchable thirst of our colleagues for knowledge. In my view, however, the prime responsibility for education, whether it be at the graduate or the postgraduate level, is unquestionably the obligation of universities. The traditional image of a professor in any ivory tower is on the way out, and information exchange and hypothesis testing is taking its place. Academics with specialized education in research techniques and the opportunity to reflect in depth on certain problems have a responsibility to communicate their findings. Disseminating the "state of the art" and synthesizing knowledge, in terms that are intelligible and applicable to everyday problems of practitioners, is a teacher's responsibility. Fortunately, there are signs that both practitioners and academics are aware of the need for an immediate consummation of this marriage between clinicians and educators.

This brings me to the role of our universities in solving problems that face us today. In many of our schools, the education of dentists and specialists in other branches of dentistry has previously incorporated little or no exposure to orthodontics. Graduates of such programs have taken it upon themselves to learn orthodontics in or through short courses offered by various continuing education enterprises that operate for financial rather than educational motives. The fault is ours, not theirs. The remedy lies in a free dissemination of information concerning the potential benefits as well as the complex biologic and technical demands that comprise modern orthodontics. An increased awareness of nonorthodontists of their patients' needs not only leads to better public service but also provides a basis for improved working relationships within the dental and nondental health specialties. Not only should all dentists be aware of and become able to recognize craniofacial problems and the possibilities of treatment; likewise, medical family practitioners, pediatricians, and others also need to have such an awareness inculcated during their education. Accomplishment of such educational objectives will obviously require increased faculty and effort on the part of university orthodontic departments.

At the graduate orthodontic educational level, an emphasis on producing a more biologically competent practitioner is essential. Although many departments pay lip service to the research and didactic component of their curriculum, these educational goals need to become a reality, not merely a chore to satisfy requirements for the accreditation of programs. It may thus be inevitable that in the future all orthodontic programs will have to be extended in duration to mect the increasing requirements of education. A 3-year rather than a 2-year program may be unavoidable, if we are to cover all the bases necessary to make our graduates both educated and competent. There is, of course, a financial aspect to such changes that affects not only the universities concerned but also students who, by prolonging training, must face an increased cost of education. Hard decisions must be made, and these may possibly result in fewer but better trained orthodontists.

The faculties of most departments at present consist entirely of orthodontists. To meet future educational objectives, it is rational to consider the incorporation of basic scientists as members of orthodontic departments within universities. Such persons, with expertise in research methods and techniques needed for the study of growth and development, form-function interrelationships, and evaluation of the relative merits of various clinical procedures, are invaluable both for the education of graduate students and for the conduct of research within orthodontic departments. Furthermore, through the incorporation of such faculty, links between orthodontics and allied basic science departments of universities can be forged, thus using the available but frequently untapped resources that exist in universities, but outside dental schools.

My final comment on orthodontic education concerns the clinical setting within which graduates receive their education and training. All too frequently (one might say almost as a rule), there now exists a startling difference between the real-life world of practice and the situation within departments where education occurs. This artificial environment that prevails in many teaching departments renders the student unprepared for the realities of entering clinical practice upon graduation. Although obvious limitations exist in terms of making a graduate clinic analogous to practice, some of the major differences can and should be removed. Instances of such differences abound. For example, many departments accept only patients who are between certain ages on the assumption that it would benefit the student most to treat children at, or about, the preadolescent growth spurt. Students who have never been exposed to patients younger or older than the prescribed limits are initially ill prepared to render the best service to such patients whom they will encounter in their first few years out of school! Departments which fail to recognize the broadening spectrum of orthodontic treatment modalities and do not expose their students to currently widespread and soundly based clinical procedures are failing in their duty. A common problem in teaching clinics and programs relates to efficiency and cost-effectiveness. Traditionally, universities have been well-endowed financially and could justify a posture of limited concern for efficient man- 
agement procedures by claiming that teaching comes first! Such an excuse is no longer viable or economically possible. Universities do not have a free flow of money; nor do they render their students a service by presenting a model for future practice that is not economically sound. It is no longer possible in most institutions for an orthodontic department to provide services at a financial loss to its dental school. With the shrinking resources available to universities over the past few years, this issue becomes a matter of survival, not merely one of teaching philosophy. Orthodontic and other clinical departments within dental schools should be run along much more business-like lines. Few, if any, students are aware of the real costs of equipment, supplies, and laboratory services and support that running a clinic operation entails. Whether one is producing teachers or practitioners for the future, we can no longer afford the luxury of disregarding the economic realities of life.

A natural question that arises is: Why should these comments, problems, and solutions concern the clinician who has his own worries in practice? We come back to the definition of altruism, or enlightened selfinterest. Our profession will advance and succeed by adapting to present needs and future opportunities. Education and training of the next generation of orthodontists, teachers, and competent clinical investigators will continue to ensure our survival because we shall be in a position to meet the demand for treatment in a manner that is both scientifically superior and economically effective. Our patients will benefit, and our image will be enhanced through the dissemination of knowledge. With the increasing delegation of chairside procedures and technical developments which make the manipulative part of orthodontics less time consuming, the orthodontist will increasingly assume the role of diagnostician and decision maker in his team. Although we do not regard ourselves as providers of "braces for money," it should be more obvious to the world at large that what, in fact, we do provide is a service based on knowledge and learning as wcll as expcrience. This is not to minimize the skill needed to do orthodontic procedures well. However, even sublime skill without profound understanding relegates our profession to a craft. Although we know that this is contrary to the truth, others need to be made more fully aware of this.

Why, then, am I optimistic? The answer lies in what I perceive to be a receptiveness within the orthodontic community to embrace such concepts which appear to be revolutionary to some but merely common sense to others. The united efforts of both educators and clinicians within our profession can solve many problems that we all face. Certainly, it should be possible to avoid repeating or perpetuating some mistakes of the past. Cooperation between practitioners and academics, based on mutual respect and the recognition of shared goals, can overcome most of the logistic problems which now hinder evolution of orthodontic education and practice. To meet the challenge of tomorrow, we must look to the youth of today. We owe it to ourselves to equip them adequately for both their destiny and ours.

Peter S. Vig

Professor and Chairman Department of Orthodontics School of Dentistry The University of Michigan Ann Arbor, Mich. 48109 